\title{
The psychophysiological correlates of cognitive dissonance
}

Gavin W. Ploger (1), University of Michigan

Johnanna Dunaway (1), Texas A\&M University

Patrick Fournier, Université de Montréal

Stuart Soroka $\mathbb{1}^{\circ}$, University of California, Los Angeles

AвSTRACT. This preregistered study uses a combination of physiological measures to explore both the activation and reduction components of cognitive dissonance theory. More precisely, we use skin conductance to identify dissonance arousal, a short-term affective response to counter-attitudinal stimuli, and then use heart rate variability to measure dissonance reduction, which reflects longer-term patterns of emotional regulation and information processing. Our preliminary tests find weak evidence of dissonance arousal and no evidence of dissonance reduction using this physiological approach. We consequently reconsider (albeit optimistically) the use of physiology in future work on cognitive dissonance. We also discuss the implications of our findings for selective exposure and motivated reasoning.

Key words: cognitive dissonance, dissonance arousal, dissonance reduction, news exposure, psychophysiology

$\mathrm{T}$ he theoretical utility of cognitive dissonance is evident from more than six decades of fruitful research (see, e.g., Cooper \& Fazio, 1984; Harmon-Jones, 2019). However, the state of dissonance has been almost exclusively inferred from observation of individual behavior in response to stimuli presumed to be dissonant, and there have been few attempts to directly measure the experience of dissonance (e.g., Croyle \& Cooper, 1983; Gerard, 1967). Moreover, one of the fundamental premises of cognitive dissonance theory has yet to be directly tested. Specifically, Festinger (1957) argued that cognitive dissonance is an uncomfortable state of physiological and psychological tension, and that individuals experiencing dissonance should be motivated to reduce their dissonant state. Some work has directly tested the physiological implications of Festinger's assertion that dissonance is a state of physiological discomfort, revealing new theoretical insights on cognitive dissonance and its underlying mechanisms (e.g., Losch \& Cacioppo, 1990). However, no work has focused on the second part of Festinger's theory: the reduction of dissonance.

Using a relatively novel psychophysiological approach to measurement, we explore physiological

doi: $10.1017 /$ pls.2021.15

Correspondence: Stuart Soroka, Communication, University of California, Los Angeles. Email: snsoroka@ucla.edu processes related to the reduction of dissonance. Doing so may be a valuable step toward better understanding cognitive dissonance theory and the processes underlying human emotional regulation and information processing. In the sections that follow, we introduce the literature on the psychophysiological study of cognitive dissonance, and then test two preregistered hypotheses about skin conductance and heart rate variability as indications of dissonance arousal and reduction, respectively. Using existing data from previous work (Fournier et al., 2020; Soroka, Fournier, \& Nir, 2019), we examine dissonance arousal and reduction in response to television news programming. We regard this context as having high external validity-news viewing is, after all, a primary context in which scholars of political communication consider cognitive dissonance. That said, our results provide very limited physiological evidence of cognitive dissonance in response to news programming. In our concluding section, we consider why this might be the case and make suggestions for further work.

\section{Cognitive dissonance}

Since Festinger's (1957) seminal work on the phenomenon, cognitive dissonance has become a foundational theory to explain how humans behave when faced with counter-attitudinal information. Festinger described 


\section{The psychophysiological correlates of cognitive dissonance}

cognitive dissonance as a state of psychological and physiological tension and discomfort between conflicting cognitive elements. Because dissonance is highly uncomfortable, individuals experiencing it should be motivated to reduce or resolve the dissonance. Festinger identified two paths to reduce dissonance: (1) changing behaviors or cognitions to achieve consonance and (2) avoiding further information and situations that would generate dissonance.

\section{Dissonance arousal}

A substantial body of work within the cognitive dissonance literature has examined the concept of dissonance arousal, the state of physiological tension that Festinger argued is central to the experience of cognitive dissonance (e.g., Higgins et al., 1979; Zanna \& Cooper, 1974). A small subset of this work examines the physiological component directly. Based on both Festinger's (1957) original theory and reconceptualizations of cognitive dissonance (e.g., Cooper \& Fazio, 1984), sympathetic nervous system activation marked by heightened skin conductance has been viewed as a likely indicator of dissonance arousal. The measure is viewed as having several advantages: first, it captures physiological tension indicative of dissonance; second, it avoids known biases associated with participants' self-reporting of their own psychological states.

However, findings in the psychophysiological literature on dissonance arousal are both varied and complex. Croyle and Cooper (1983) found that a dissonanceinducing task increased participants' skin conductance but did not cause any attitude change. They argued that this was because participants misattributed the dissonance arousal to the device used to record physiological responses, rather than to the discomfort of dissonance itself. Elkin and Leippe (1986) found that a dissonance task raised skin conductance and did cause attitude change. Etgen and Rosen (1993), in contrast, found no evidence of increased skin conductance in response to dissonance induction. Their operationalization of skin conductance was different from prior studies, as was their dissonance manipulation. Even so, their results may raise questions about the generalizability of previous findings.

Perhaps the clearest psychophysiological study on dissonance arousal came from Losch and Cacioppo (1990), who used an elaborated version of Zanna and Cooper's (1974) misattribution paradigm to disentangle general arousal from participants' affective interpretation of their own arousal. Rather than the potentially negative cue of an experimental pill used in the broader misattribution literature (e.g., Higgins et al., 1979; Zanna \& Cooper, 1974), Losch and Cacioppo (1990) used prism goggles as a more affectively neutral stimulus for the misattribution paradigm. Consistent with Croyle and Cooper (1983) and Elkin and Leippe (1986), Losch and Cacioppo (1990) found that participants who completed a standard dissonance-inducing task experienced increased skin conductance and that the level of arousal was the same whether participants were primed to interpret their arousal positively or negatively. However, participants who were primed to interpret the induced arousal positively (i.e., those for whom positive arousal would be attributed to the prism goggles and negative arousal would be implicitly attributed to dissonance) showed greater attitude change than participants in the other conditions. Based on these findings, Losch and Cacioppo (1990) suggested that people are not motivated to reduce dissonance arousal itself, as Festinger (1957) originally suggested, but instead to reduce the negative affect associated with that arousal.

Both Elkin and Leippe (1986) and Losch and Cacioppo (1990) also found that dissonance arousal remained high several minutes after attitude change, suggesting that dissonance arousal may be reduced gradually over time rather than immediately by attitude change (as Festinger's theory would suggest). We regard these findings as not only contrary to Festinger's account but also atypical in the psychophysiological literature. Given our expectations based on both results from our own work (e.g., Dunaway \& Soroka, 2019; Soroka, Fournier, \& Nir, 2019; Soroka \& McAdams, 2015) as well as standards in psychophysiological methodology developed in large part by Cacioppo (e.g., Cacioppo et al., 2007), we expect changes in skin conductance to be more temporary. That said, given that the long-lasting increase in physiological arousal was found in two separate studies, we are hesitant to attribute it to faulty measurement. Accordingly, we consider the possibility of long-term increases in physiological arousal in this study.

On balance, we see past work as suggesting that dissonance arousal is associated with increased skin conductance. The affective interpretation of dissonance seems to be especially important (Losch \& Cacioppo, 1990). However, the duration of heightened skin conductance may be longer than we would expect if attitude change reduced that increased activation relatively quickly, as Festinger (1957) suggested. 


\section{Gavin Ploger et al.}

\section{Dissonance reduction}

Research has focused primarily on the first part of Festinger's claim, namely, that dissonance arousal is an uncomfortable state of physiological tension. The second part, that individuals experiencing dissonance are motivated to reduce it, has not been directly (i.e., psychophysiologically) tested. The broader dissonance literature has provided considerable behavioral evidence to support the claim that individuals seek to reduce dissonance, but there has been no direct examination of the physiological indicators of those efforts.

As there is no research that directly explores dissonance reduction, we turn to a related body of work to inform our investigation. Motivated reasoning theories hold that people attempt to process counter-attitudinal information in a way that minimizes dissonance (e.g., Kunda, 1990; Leeper \& Slothuus, 2014). Thus, psychophysiological research on motivated reasoning might help illustrate patterns of dissonance reduction. Westen et al. (2006) found that tasks intended to elicit motivated reasoning increased activation in areas of the brain normally associated with implicit emotion regulation and "hot" reasoning. This work connects clearly with the literature on cognitive dissonance and especially to studies that suggest the importance of reducing negative affect rather than dissonance arousal more broadly (Losch \& Cacioppo, 1990). Moving from motivated reasoning to cognitive dissonance, Westen et al.'s (2006) findings suggest that people who experience dissonance may engage in emotional regulation to reduce that dissonance. Consequently, we may be able to detect dissonance reduction by examining physiological markers of emotional regulation.

Although the majority of physiological research on cognitive dissonance has focused on skin conductance, it is likely not an appropriate measure for exploring emotional regulation. Emotional regulation implies both the activation of an emotional response and the subsequent processes by which that activation is managed, corresponding in this case to dissonance arousal and dissonance reduction, respectively. Skin conductance is a useful indicator of dissonance arousal, but it does not reflect the more complex affective and cognitive processes that underlie dissonance reduction. However, emotional regulation can be captured using other psychophysiological measures. We argue for the use of heart rate variability (HRV), a measure that may reflect both dissonance arousal and individuals' attempts to reduce dissonance through emotional regulation and information processing, as implicated by results from Westen et al. (2006; see also Losch \& Cacioppo, 1990).

There is a small but growing body of psychophysiological work focusing on HRV (Potter \& Bolls, 2011). Extant theories of HRV draw heavily from psychology and broadly conceive of HRV as an indicator of attention allocation (Porges, 1992; Thayer \& Lane, 2000). Because attention allocation allows individuals to select and exclude information in their environment, attention allocation is a critical facilitator of information processing and emotional regulation (Appelhans \& Luecken, 2006). Consistent with this approach, HRV has been found to be associated with the use of coping strategies in response to stress among both university students (Fabes \& Eisenberg, 1997) and grade school children (Fabes et al., 1993); with increased defensive coping among women in response to induced states of fear (Pauls \& Stemmler, 2003); and with coping and acceptance in response to grief (O'Connor et al., 2002). Studies have also found links between HRV and various forms of anxiety (Fuller, 1992; Mezzacappa et al., 1997; Sgoifo et al., 2003; Thayer et al., 1996) and depression (Cohen et al., 2003; O'Connor et al., 2002; Rechlin et al., 1994), as both anxiety and depression relate to the ability to successfully regulate autonomic responses to negative emotions and stress. HRV also accounts for both individual differences and within-person variation in regulated emotional responses to environmental stimuli (Appelhans \& Luecken, 2006), although the present study lacks the data required for an in-depth exploration of these differences. Overall, evidence from psychological research generally supports the notion that $\mathrm{HRV}$ is a dynamic indicator of the capacity for emotional regulation. Thus, if dissonance reduction occurs through emotional regulation, we suggest that HRV should be uniquely suited to measuring dissonance reduction.

Moreover, a focus on heart rate variability enables exploration of the competing influences of dissonance arousal and dissonance reduction. Heart rate is affected by both the sympathetic nervous system (reflecting arousal and activation) and the parasympathetic nervous system (reflecting attention and effortful processing) (Potter \& Bolls, 2011). Dissonance arousal will create physiological activation (reflected by increased heart rate). Dissonance reduction occurs through emotional regulation and cognitive processing (reflected by decreased heart rate). Because these processes push heart rate in opposite directions, average heart rate over time may stay relatively stable even during the experiences of 


\section{The psychophysiological correlates of cognitive dissonance}

dissonance arousal and dissonance reduction. The advantage of HRV over heart rate itself is that the former enables an exploration of how much heart rate varies in response to both of these competing influences.

We suggest that, just as the nature of dissonance arousal has been clarified by direct examination of its psychophysiological indicators, a psychophysiological examination of the process of dissonance reduction will allow us to further test the drivers and implications of cognitive dissonance. Moreover, a direct indicator of the effort to reduce dissonance will allow researchers to distinguish between people who do not feel dissonance, people who feel and seek to reduce dissonance, and people who feel dissonance but do not actively seek to reduce it. Distinguishing between these possibilities is of considerable significance for research on selective exposure or motivated reasoning in the context of political communication.

\section{Hypotheses}

Formally stated, our hypotheses are as follows:

H1: Participants exposed to a counter-attitudinal news story will experience increased skin conductance, reflecting increased dissonance.

H2: Participants exposed to a counter-attitudinal news story will experience increased heart rate variability as a consequence of both increased physiological arousal and increased emotional regulation.

It is worth noting that a small body of research in political science has found inconsistencies in results from psychophysiological work. More specifically, recent work has failed to replicate prior research linking political ideology and physiologically captured negativity biases (Bakker et al., 2020; Fournier et al., 2020; Osmundsen et al., in press). For us, this recent work has highlighted the need to be cautious in our use and interpretation of physiological measures. Unlike the unreplicable early research on psychophysiology and political ideology, our interpretation of HRV in this study does not view physiological responses as reflections of underlying biopolitical predispositions, but rather as in-the-moment reactions to and processing of media content. This perspective is more common in work in communication (see, e.g., Lang et al., 2000; Soroka,
Fournier, Nir, \& Hibbing, 2019), and we regard it as less theoretically fraught.

\section{Method}

This study relied on psychophysiological data from over 1,100 respondents across 17 countries, from Soroka, Fournier, and Nir (2019; see also Fournier et al., 2020). ${ }^{1}$ Details on data gathering are available in the appendix to that paper and in the supplementary material for this article. The original data collection and analysis were focused on hypotheses unrelated to those examined in the current study. However, the data were well suited to a physiological exploration of dissonance because of the recording of high-quality physiological data as well as the very broad sample.

Most importantly, the video stimuli used in the study seemed to be well suited to the present investigation. Most videos were, by design, not obviously ideologically slanted, but one video was a somewhat left-leaning news story about May Day labor marches against austerity in Europe. To be clear, the BBC reporting in the story was entirely objective, but the majority of the story consisted of footage of large labor marches protesting both labor conditions and potential costs of austerity to workers of the European Union (EU). The EU element was slightly complicating since it put workers' concerns in line with right-wing anti-EU concerns, but we considered the general political tone of the content as left-leaning. Thus, we expected this story to create cognitive dissonance for right-wing viewers but not for left-wing viewers. Because the six other international news stories were, in our view, not at all ideologically slanted, we expected to see dissonance only in response to the May Day story.

This study did not include a treatment per se. Rather, our analysis hinged on a comparison of HRV across individuals who were more or less likely (based on political ideology) to feel cognitive dissonance in response to a $\mathrm{BBC}$ news story about Labor Day marches across Europe. That story was 2 minutes and 45 seconds

\footnotetext{
${ }^{1}$ We do not report results here from a preliminary analysis that motivated both the pre-analysis plan and the current study, namely, an exploration of data gathered by Dunaway and Soroka (2019), which focused on the impact of screen size on psychophysiological reactions to television news stories. The advantage of those data was that experimental stimuli were relatively clearly ideological; however, the student sample meant that most of the respondents were liberal. We found no evidence supporting our hypotheses in those data; but, given the limitations of the sample and the exploratory nature of those analyses, we thought it worthwhile to proceed with formally testing our expectations using a second data set.
} 


\section{Gavin Ploger et al.}

long. ${ }^{2}$ The first 18 seconds were an introduction with a talking head. The remainder of the story featured videos of different Labor Day marches across European countries, including lots of people, signs, chanting, and police.

We relied on the following physiological measures:

Skin conductance (SC): We measured SC in microsiemens. We considered several possibilities for managing variation in story length: we examined SC averaged over the length of the story, over the first 1 minute and 2 minutes of each story (as above), and at 1 -second intervals. Since results in this instance are the same regardless of which level of analysis we specify, we use the far simpler respondent-story-level data here. This has the advantage of matching our analyses of HRV, which are necessarily at the respondentstory level because HRV is measured over the duration of a story.

Heart rate variability: We measured HRV using two different approaches: the standard deviation of $\mathrm{NN}$ intervals (SDNN) and the root mean square of successive differences (RMSSD). These are marginally different measures, both now standard in the field (Appelhans \& Luecken, 2006; Task Force, 1996). Results for RMSSD were the same as results for SDNN; for the sake of parsimony, we present only the results for RMSSD here. We captured HRV over the duration of each story, though it should be noted that the stories ranged from 2 to 4 minutes. There were several possible ways to deal with this. The first was to include the length of the story (in seconds) as a control variable. The second was to focus on just the first minute, or just the first 2 minutes, of each story. We explored each of these possibilities as a test of the robustness of our findings (see the supplementary material).

We tested our hypotheses using regression techniques. For both SC and HRV, we regressed the physiological

\footnotetext{
${ }^{2}$ Because participants viewed seven news stories in total, of which only one was clearly counter-attitudinal (for one portion of the sample), this study should be viewed as a within-respondent experimental design in which each participant was exposed to control and treatment conditions at different points in time (see, e.g., Druckman et al., 2011; McDermott, 2002).
}

measure on participant ideology, measured using either (1) a left-right ideology scale or (2) a Wilson-Patterson index. We included some basic demographic controls: gender, age, education, and income. We modeled responses to multiple news stories so that we could compare responses to the Labor Day story, which should have produced dissonance, with responses to the other stories, which should not have produced dissonance. We conducted our tests with the entire sample as well as with regional subsamples (i.e., European, North American, etc.) and country subsamples.

To be clear: our hypotheses suggested increases in both SC and HRV among conservative participants in response to the Labor Day story, relative to liberal participants and relative to other news stories. Our use of subsample analysis was not driven by additional hypotheses about differences across individuals, although we considered the possibility that cognitive dissonance would be most evident among our European subsample, given that this was the region where the Labor Day marches took place.

The main survey measures used in our analysis were based on the following questions:

Gender: What is your gender? [Coded as binary, where $1=$ female]

Age: In what year were you born? [Coded as age in years]

Education: What is the highest level of education you have completed? [Coded as binary, where $1=$ more than high school]

Income: Thinking about other families in your country, would you say your family's income is ... ? [Captured and included as a 7-point scale, from "much lower than average" to "much higher than average"]

Left-right ideology: In politics, people sometimes talk of left and right. Where would you place yourself on a scale from 0 to 10 , where 0 means the left and 10 means the right? [Captured and included as a $0-10$ scale]

Wilson-Patterson index: Please indicate whether you agree or disagree (or are uncertain) with regard to each topic listed below: abortion, capitalism, censorship, death penalty, gay marriage, gun control, immigration, military spending, obedience, patriotism, pollution control, socialism, tax cuts, and women's equality. Items are reverse-coded where necessary so that increasing values of the scale indicate right-wing 


\section{The psychophysiological correlates of cognitive dissonance}

Table 1. Psychophysiological responses to the May Day story.

\begin{tabular}{|c|c|c|c|c|}
\hline & SC1 & $\mathrm{SC} 2$ & HRV1 & HRV2 \\
\hline Gender & $\begin{array}{l}-0.050 \\
(0.061)\end{array}$ & $\begin{array}{l}-0.048 \\
(0.061)\end{array}$ & $\begin{array}{r}-4.460 \\
(4.429)\end{array}$ & $\begin{array}{c}-4.310 \\
(4.424)\end{array}$ \\
\hline Age & $\begin{array}{l}-0.003 \\
(0.002)\end{array}$ & $\begin{array}{l}-0.003 \\
(0.002)\end{array}$ & $\begin{array}{c}-1.385^{* *} \\
(0.175)\end{array}$ & $\begin{array}{c}-1.389 * \\
(0.174)\end{array}$ \\
\hline Education & $\begin{array}{l}-0.078 \\
(0.062)\end{array}$ & $\begin{array}{l}-0.044 \\
(0.063)\end{array}$ & $\begin{array}{l}-0.739 \\
(4.520)\end{array}$ & $\begin{array}{l}-0.160 \\
(4.594)\end{array}$ \\
\hline Income & $\begin{array}{c}0.019 \\
(0.022)\end{array}$ & $\begin{array}{c}0.018 \\
(0.021)\end{array}$ & $\begin{array}{l}-0.576 \\
(1.500)\end{array}$ & $\begin{array}{l}-0.591 \\
(1.497)\end{array}$ \\
\hline Left-right ideology & $\begin{array}{l}-0.003 \\
(0.012)\end{array}$ & & $\begin{array}{c}0.007 \\
(0.861)\end{array}$ & \\
\hline Wilson-Patterson index & & $\begin{array}{c}0.256 \\
(0.136)\end{array}$ & & $\begin{array}{c}5.883 \\
(9.839)\end{array}$ \\
\hline Constant & $\begin{array}{c}0.108 \\
(0.146) \\
\end{array}$ & $\begin{array}{l}-0.018 \\
(0.144) \\
\end{array}$ & $\begin{array}{c}168.139 * * \\
(10.469)\end{array}$ & $\begin{array}{c}165.742 * \\
(10.337)\end{array}$ \\
\hline Observations & 593 & 594 & 684 & 685 \\
\hline $\mathrm{F}(5)$ & 0.763 & 1.473 & $12.656^{* * *}$ & $12.776 * *$ \\
\hline$R^{2}$ & 0.006 & 0.012 & 0.085 & 0.086 \\
\hline
\end{tabular}

ideology. Not all items are equally valid or scale reliably across countries, so we use a measure that is adjusted by country as outlined in Fournier et al. (2020). [Rescaled from 0 to 1]

All the data and scripts used for the analyses that follow are archived in the Harvard Dataverse at https:// doi.org/10.7910/DVN/JNN55B.

\section{Results}

Analyses of both SC and HRV in response to the May Day story are shown in Table 1, excluding respondents for whom physiological measures were problematic (see Soroka, Fournier, \& Nir, 2019 for details). (Sample size was reduced somewhat by flawed physiological data, but primarily by the randomization, which means that not all respondents viewed all stories.) We present models that include either left-right ideology or the Wilson-Patterson index.

Consistent with $H 1$, we found a weak positive relationship between ideology and SC, such that right-wing participants exhibited slightly greater skin conductance than left-wing participants when exposed to the May Day story. This was the case only when we used the Wilson-Patterson scale (column 2 of Table 1), however; and this relationship narrowly missed standard criteria for statistical significance ( $p=.059$, two-tailed test). Appendix Tables $1 \mathrm{~A}$ and $1 \mathrm{~B}$ show similar models estimated across the other stories included in the experiment; none showed any relationship between political ideology and SC. Thus, we did not find much evidence in support of H1: right-leaning respondents did not appear to consistently experience heightened skin conductance in response to the May Day story.

The latter columns of Table 1 do not show support for H2. There was no hint of a relationship between left-right ideology and HRV, and there was a positive association between the Wilson-Patterson index and HRV, but well below standard levels of statistical significance ( $p=.550$, two-tailed test). These data did not suggest that right-leaning participants experience heightened HRV in response to the May Day storythat is, we see no indication of effort amongst rightwing participants to reduce dissonance through emotional regulation (at least when measured using HRV). There also was no sign of an association between ideology and HRV in the other news stories, for which we had no expectation of cognitive dissonance. (These estimates are shown in Appendix Tables 1C and 1D.)

Our results were robust to the exclusion of control variables and different specifications of the physiological measures, and consistent when the analyses were restricted to single-country samples as well. There was also no hint of stronger results in European countries (where the May Day marches took place) than in other countries where the story would presumably be less salient. It is unclear whether this is because our story was not sufficiently dissonance-inducing or because dissonance reduction is not reliably captured 


\section{Gavin Ploger et al.}

by HRV. ${ }^{3}$ We lean toward the former possibility but have no empirical evidence to support that conjecture. We discuss this issue in more detail in the next section.

\section{Discussion}

\section{Dissonance arousal and skin conductance}

Given that the secondary data we relied on were not collected with dissonance in mind, it is perhaps not surprising that the relationship we found between ideology and skin conductance was relatively weak. However, prior psychophysiological research on cognitive dissonance has provided strong evidence that induced dissonance can be measured using skin conductance (Croyle \& Cooper, 1983; Elkin \& Leippe, 1986; Losch \& Cacioppo, 1990; cf. Etgen \& Rosen, 1993). Why, then, was the effect we found so modest?

The difference is not that we focused on politics, whereas previous research focused on potentially more dissonant topics. Vraga (2015) showed that traditional dissonance paradigms are effective for inducing dissonance in a political context. It seems more likely that the kind of dissonance induced by more traditional experimental treatments in the lab is different from the kind of dissonance we explored here. A common way to induce dissonance is to ask participants to volunteer to write a counter-attitudinal essay. Essentially, the logic is that participants experience dissonance as a consequence of freely engaging in behavior that conflicts with their beliefs. The conflicting elements in that paradigm (i.e., the elements that create dissonance) are the participants' voluntary behaviors (albeit at the request of researchers) and the participants' beliefs. What we explored here was slightly different: rather than creating dissonance between participants' behaviors and beliefs, we attempted to create dissonance between participants' beliefs and incoming information. Moreover, they did not explicitly agree to being exposed to said counter-attitudinal information in advance. Thus, the exposure was not only involuntary but also without advance warning.

It is worth nothing, then, that while previous research has demonstrated that exposure to counter-attitudinal communication can induce dissonance (e.g., Cooper et al., 1974), there is less evidence to support this in the context of involuntary, unanticipated exposure to

\footnotetext{
${ }^{3}$ There is another alternative, namely, that Festinger's theory or our interpretation of this theory is incorrect. We discuss this possibility later.
}

counter-attitudinal information. In the context of voluntary exposure, Freedman and Sears (1965) argued the knowledge that other people disagree with one's position - even prior to exposure to actual disagreement—can be sufficient to create dissonance. Given what appears to us to be a relative paucity of research that explicitly explores dissonance in relation to unanticipated counter-attitudinal communication, especially in the context of involuntary exposure, this may be a fruitful topic for future work.

It may also be argued that, because our participants were involuntarily exposed to counter-attitudinal communication, we should not have expected to see evidence of dissonance. Forced compliance can make it easy for people to dismiss dissonance (e.g., Festinger \& Carlsmith, 1959). This could be true to some extent; however, there are two reasons this may not be the case. First, although our study forcibly exposed people to a counterattitudinal stimulus, the dissonance we hypothesized was not between a counter-attitudinal behavior and a cognition. Instead, we expected dissonance between participants' political beliefs and the knowledge of information that conflicts with those beliefs and, perhaps, the knowledge that others apparently disagree with them as well. Second, even if people could easily dismiss the dissonance from our counter-attitudinal stimulus, dismissing dissonance requires first experiencing it. Thus, we suggest that dissonance is a plausible outcome of involuntary exposure to counter-attitudinal communication, although this kind of dissonance may be less intense than-or even qualitatively different from-dissonance between cognition and voluntary behavior.

Another distinct possibility is that the May Day story was only mildly counter-attitudinal, and thus it did not arouse as much dissonance as the intensely counterattitudinal stimuli used in classic dissonance research. To our knowledge, our study was the first psychophysiological research to induce dissonance using non-artificial stimuli. In that light, it would be surprising if the effects we found were as strong as those found in lab studies using stimuli designed solely to induce dissonance. And it is entirely possible that the May Day story was relatively low in dissonance, and that other political news stories might have induced stronger dissonance more in line with traditional experimental paradigms. Nevertheless, we regard it as unlikely that the differences between our findings and those of past work are solely attributable to idiosyncrasies of our stimuli. In other words, we view our findings as an indication that the May Day story may not be unusual among news stories in its failure to induce 


\section{The psychophysiological correlates of cognitive dissonance}

strong dissonance. Indeed, even with strong ideological primes, Metzger et al. (2015) found that exposure to counter-attitudinal news sources and news stories resulted in only small (albeit still significant) increases in dissonance. If much of the information that people encounter in their daily lives is, like the May Day story, not strongly dissonant, it may be that dissonance is not a phenomenon that people experience with enough intensity and regularity to meaningfully influence their behavior. This possibility has major implications for the literature on selective exposure.

Research on selective exposure draws heavily from the literature on cognitive dissonance; indeed, a fundamental assumption of selective exposure is that people avoid counter-attitudinal information because it creates dissonance (Hart et al., 2009). However, more recent work has suggested that people do not selectively avoid counter-attitudinal information-instead, they primarily selectively approach pro-attitudinal information (Garrett, 2009; Garrett \& Stroud, 2014). While the logic underlying the use of dissonance as a mechanism for selective avoidance is straightforward, it is less clear how dissonance might drive tendencies for selective approach. Our findings suggest that people may not experience much dissonance when they are exposed to counter-attitudinal information (see also Freedman \& Sears, 1965), thus undermining the presumed mechanism for selective avoidance and, perhaps, partially explaining why selective avoidance is not as prevalent as selective approach. Consistent with this possibility, Metzger et al. (2015) argued that selective exposure is driven not by dissonance but by perceptions of credibility: people prefer news they view as credible, and their perceptions of credibility are systematically biased against counter-attitudinal news. Thus, even though people prefer pro-attitudinal news, this selection bias is largely unrelated to dissonance.

If it is the case that people generally do not perceive real-world counter-attitudinal information as dissonant, it behooves scholars of cognitive dissonance to critically reevaluate the relevance of dissonance theory to explanations of human behavior outside the lab. Future research should test the psychophysiological implications of cognitive dissonance theory across a wide variety of stimuli, including both traditional experimental paradigms for inducing dissonance and stimuli representative of real-world information. Moreover, without diverse, representative samples, even inferences derived from internally valid designs should be regarded with caution. Our study, which features a cross-national sample, is a step forward in this regard, but we hope that researchers interested in this area continue to systematically investigate dissonance outside of typical undergraduate samples.

\section{Dissonance reduction and heart rate variability}

Our finding that right-leaning participants did not engage in dissonance reduction after exposure to the May Day story follows naturally from our finding that these participants felt only slight dissonance in response to the story. Without evidence of strong effects on dissonance arousal, we would be surprised if we found evidence of strong effects on dissonance reduction.

We speculate that this null finding may be attributable to one or both of two factors above and beyond the May Day story's limited induction of dissonance. First, it may be that dissonance reduction occurs over a longer time frame than either of our data sets allow us to investigate. Both Elkin and Leippe (1986) and Losch and Cacioppo (1990) found that dissonance arousal took several minutes to dissipate. Our primary data here were limited to just under 3 minutes of exposure to a single news story; it is plausible that our data provided too narrow a window to properly analyze dissonance reduction as a gradual phenomenon. As we discussed earlier, the pattern of long-lasting physiological arousal captured by Elkin and Leippe (1986) and Losch and Cacioppo (1990) is extremely unusual in comparison to expectations set by other psychophysiological work (e.g., Cacioppo et al., 2007). Nonetheless, it may be productive for future work to take seriously the possibility that dissonance reduction occurs over longer time periods than those typically examined by psychophysiological research.

It may also be that HRV is not a suitable measure for dissonance reduction. Lacking alternative measures of dissonance reduction to which we can compare HRV, it is difficult to establish what dissonance reduction "should" look like. We believe our theoretical justifications for the use of HRV are convincing but, as we discussed earlier, HRV is a measure that simultaneously represents several competing psychophysiological systems (e.g., Appelhans \& Luecken, 2006; Task Force, 1996). As such, it may be that there is simply too much noise in HRV for it to be appropriate for measuring dissonance reduction.

Although both of these explanations for our null findings are possible, we do not regard them as especially plausible. As we have said, there is strong reason to believe that dissonance arousal should be reduced within 


\section{Gavin Ploger et al.}

the time span captured by our data, and, without additional evidence, we have no reason to discount HRV as a measure of dissonance reduction. While we acknowledge these possibilities, we also consider the implications of our null dissonance reduction findings for our understanding of how people process political information. Motivated reasoning theories assume counter-attitudinal information creates dissonance that people are motivated to reduce through biased processing (e.g., Kunda, 1990; Leeper \& Slothuus, 2014). ${ }^{4}$ However, as our findings suggest, counter-attitudinal information may not always create dissonance (also see Metzger et al., 2015). It may also be unsafe to assume that individuals are motivated and able to reduce dissonance via effortful processing and emotional regulation, key mechanisms of motivated reasoning. There is as yet no evidence that these processes actually occur in response to dissonance, let alone that they are successful in reducing dissonance. The findings from our study are inconclusive on this point: we find no evidence of dissonance reduction, but we also show only limited evidence of dissonance in the first place.

Our study may also help inform a debate within the broader literature on motivated reasoning. This debate focuses on how motivated reasoning affects the processing of partisan information to shape opinion. One account holds that people rely on party cues as a basis for low-effort heuristic processing of information; another suggests that party cues motivate people to engage in high-effort directional processing of information (i.e., motivated reasoning) to ensure that attitudes based on new information are consistent with party identification (Petersen et al., 2013). This second view is more consistent with the dissonance-reduction aspect of Festinger's (1957) theory and is supported by existing research (Bolsen et al., 2014; Petersen et al., 2013). However, our null results regarding dissonance reduction may provide some evidence in support of the party-cue-as-heuristic account, in which exposure to counter-attitudinal information reduces the need for effortful processing. We suggest that our study adds to the cross-study variation in findings about whether and how partisan cues interact with information processing

\footnotetext{
${ }^{4}$ Note that Taber and Lodge (2006) argued that their theory of affect-driven motivated reasoning is quite distinct from cognitive dissonance, which they suggest relies more on "cold" cognition. However, Festinger's (1957) proposition was that dissonance is a state of discomfort that includes cognitive, affective, and physiological experiences; thus, motivated reasoning and cognitive dissonance may not be as dissimilar as Taber and Lodge (2006) suggested.
}

(Peterson, 2017). Thus, we echo recent arguments that additional research is needed to more completely test the theoretical implications of the party-cues debate (Leeper \& Slothuus, 2014; Peterson, 2017).

\section{Supplementary Materials}

To view supplementary material for this article, please visit http://dx.doi.org/10.1017/pls.2021.15.

\section{References}

Appelhans, B. M., \& Luecken, L. J. (2006). Heart rate variability as an index of regulated emotional responding. Review of General Psychology, 10(3), 229-240. https:// doi.org/10.1037/1089-2680.10.3.229

Bakker, B. N., Schumacher, G., Gothreau, C., \& Arceneaux, K. (2020). Conservatives and liberals have similar physiological responses to threats. Nature Human Behaviour, 4, 613-621. https://doi.org/10.1038/s41562-020-0823-Z

Bolsen, T., Druckman, J. N., \& Cook, F. L. (2014). The influence of partisan motivated reasoning on public opinion. Political Behavior, 36(2), 235-262. https://doi.org/10.1007/ s11109-013-9238-0

Cacioppo, J. T., Tassinary, L. G., \& Berntson, G. (2007). Handbook of psychophysiology. Cambridge University Press.

Cohen, H., Kaplan, Z., Kotler, M., Mittelman, I., Osher, Y., \& Bersudsky, Y. (2003). Impaired heart rate variability in euthymic bipolar patients. Bipolar Disorders, 5(2), 138-143. https://doi.org/10.1034/j.1399-5618.2003.00027.x

Cooper, J., Darley, J. M., \& Henderson, J. E. (1974). On the effectiveness of deviant- and conventional-appearing communicators: A field experiment. Journal of Personality and Social Psychology, 29(6), 752-757. https://doi.org/10.1037/ h0036200

Cooper, J., \& Fazio, R. H. (1984). A new look at dissonance theory. In L. Berkowitz (Ed.), Advances in experimental social psychology (Vol. 17, pp. 229-266). Elsevier. https://doi.org/ 10.1016/S0065-2601(08)60121-5

Croyle, R. T., \& Cooper, J. (1983). Dissonance arousal: Physiological evidence. Journal of Personality and Social Psychology, 45(4), 782-791. https://doi.org/10.1037/00223514.45.4.782

Druckman, J. N., Green, D. P., Kuklinski, J. H., \& Lupia, A. (2011). Cambridge handbook of experimental political science. Cambridge University Press.

Dunaway, J., \& Soroka, S. (2019). Smartphone-size screens constrain cognitive access to video news stories. Information, 


\section{The psychophysiological correlates of cognitive dissonance}

Communication \& Society, 24(1), 69-84. https://doi.org/ 10.1080/1369118X.2019.1631367

Elkin, R. A., \& Leippe, M. R. (1986). Physiological arousal, dissonance, and attitude change: Evidence for a dissonancearousal link and a "don't remind me" effect. Journal of Personality and Social Psychology, 51(1), 55-65.

Etgen, M. P., \& Rosen, E. F. (1993). Cognitive dissonance: Physiological arousal in the performance expectancy paradigm. Bulletin of the Psychonomic Society, 31(3), 229-231. https://doi.org/10.3758/BF03337331

Fabes, R. A., \& Eisenberg, N. (1997). Regulatory control and adults' stress-related responses to daily life events. Journal of Personality and Social Psychology, 73(5), 1107-1117. https:// doi.org/10.1037/0022-3514.73.5.1107

Fabes, R. A., Eisenberg, N., \& Eisenbud, L. (1993). Behavioral and physiological correlates of children's reactions to others in distress. Developmental Psychology, 29(4), 655-663. https:// doi.org/10.1037/0012-1649.29.4.655

Festinger, L. (1957). A theory of cognitive dissonance. Stanford University Press.

Festinger, L., \& Carlsmith, J. M. (1959). Cognitive consequences of forced compliance. Journal of Abnormal and Social Psychology, 58(2), 203-210. https://doi.org/10.1037/ h0041593

Fournier, P., Soroka S., \& Nir, L. 2020. Negativity biases and political ideology: A comparative test across 17 countries. American Political Science Review, 114(3), 775-791. https:// doi.org/10.1017/S0003055420000131

Freedman, J. L., \& Sears, D. O. (1965). Selective exposure. In L. Berkowitz (Ed.), Advances in experimental social psychology (Vol. 2, pp. 57-97). Elsevier. https://doi.org/ 10.1016/S0065-2601(08)60103-3

Fuller, B. F. (1992). The effects of stress-anxiety and coping styles on heart rate variability. International Journal of Psychophysiology, 12(1), 81-86. https://doi.org/10.1016/ 0167-8760(92)90045-D

Garrett, R. K. (2009). Politically motivated reinforcement seeking: Reframing the selective exposure debate. Journal of Communication, 59(4), 676-699. https://doi.org/10.1111/ j.1460-2466.2009.01452.x

Gerard, H. B. (1967). Choice difficulty, dissonance, and the decision sequence. Journal of Personality, 35(1), 91-108. https://doi.org/10.1111/j.1467-6494.1967.tb01417.x

Garrett, R. K., \& Stroud, N. J. (2014). Partisan paths to exposure diversity: Differences in pro- and counterattitudinal news consumption. Journal of Communication, 64(4), 680-701. https://doi.org/10.1111/jcom.12105
Harmon-Jones, E. (2019). Cognitive dissonance: Reexamining a pivotal theory in psychology. American Psychological Association.

Hart, W., Albarracín, D., Eagly, A. H., Brechan, I., Lindberg, M. J., \& Merrill, L. (2009). Feeling validated versus being correct: A meta-analysis of selective exposure to information. Psychological Bulletin, 135(4), 555-588. https://doi.org/ 10.1037/a0015701

Higgins, E. T., Rhodewalt, F., \& Zanna, M. P. (1979). Dissonance motivation: Its nature, persistence, and reinstatement. Journal of Experimental Social Psychology, 15 (1), 16-34. https://doi.org/10.1016/0022-1031(79)90015-5

Kunda, Z. (1990). The case for motivated reasoning. Psychological Bulletin, 108(3), 480-498. https://doi.org/ 10.1037/0033-2909.108.3.480

Lang, A., Zhou, S., Schwartz, N., Bolls, P. D., \& Potter, R. F. (2000). The effects of edits on arousal, attention, and memory for television messages: When an edit is an edit can an edit be too much? Journal of Broadcasting \& Electronic Media, 44(1), 94-109. https://doi.org/10.1207/s15506878jobem4401_7

Leeper, T. J., \& Slothuus, R. (2014). Political parties, motivated reasoning, and public opinion formation. Political Psychology, 35(Suppl. 1), 129-156. https:/doi.org/10.1111/ pops.12164

Losch, M. E., \& Cacioppo, J. T. (1990). Cognitive dissonance may enhance sympathetic tonus, but attitudes are changed to reduce negative affect rather than arousal. Journal of Experimental Social Psychology, 26(4), 289-304. https:// doi.org/10.1016/0022-1031(90)90040-S

McDermott, R. (2002). Experimental methods in political science. Annual Review of Political Science, 5(1), 31-61.

Metzger, M. J., Hartsell, E. H., \& Flanagin, A. J. (2015). Cognitive dissonance or credibility? A comparison of two theoretical explanations for selective exposure to partisan news. Communication Research, 47(1), 3-28. https://doi.org/ 10.1177/0093650215613136

Mezzacappa, E., Tremblay, R. E., Kindlon, D., Saul, J. P., Arseneault, L., Seguin, J., Pihl, R. O., \& Earls, F. (1997). Anxiety, antisocial behavior, and heart rate regulation in adolescent males. Journal of Child Psychology and Psychiatry, 38(4), 457-469. https://doi.org/10.1111/j.1469-

7610.1997.tb01531.x

O’Connor, M.-F., Allen, J. J. B., \& Kaszniak, A. W. (2002). Autonomic and emotion regulation in bereavement and depression. Journal of Psychosomatic Research, 52(4), 183-185. https://doi.org/10.1016/S0022-3999(02)00292-1

Osmundsen, M., Hendry, D., Laustsen, L., Smith, K., and Petersen, M. B. (in press). The psychophysiology of political ideology: Replications, reanalysis, and recommendations. Journal of Politics. 


\section{Gavin Ploger et al.}

Pauls, C. A., \& Stemmler, G. (2003). Repressive and defensive coping during fear and anger. Emotion, 3(3), 284-302. https:// doi.org/10.1037/1528-3542.3.3.284

Peterson, E. (2017). The role of the information environment in partisan voting. Journal of Politics, 79(4), 1191-1204.

Petersen, M. B., Skov, M., Serritzlew, S., \& Ramsøy, T. (2013). Motivated reasoning and political parties: Evidence for increased processing in the face of party cues. Political Behavior, 35(4), 831-854. https://doi.org/10.1007/s11109. 012-9213-1

Porges, S. W. (1992). Vagal tone: A physiologic marker of stress vulnerability. Pediatrics, 90(3 Pt. 2), 498-504.

Potter, R. F., \& Bolls, P. (2011). Psychophysiological measurement and meaning: Cognitive and emotional processing of media. Routledge.

Rechlin, T., Weis, M., Spitzer, A., \& Kaschka, W. P. (1994). Are affective disorders associated with alterations of heart rate variability? Journal of Affective Disorders, 32(4), 271-275. https://doi.org/10.1016/0165-0327(94)90091-4

Sgoifo, A., Braglia, F., Costoli, T., Musso, E., Meerlo, P., Ceresini, G., \& Troisi, A. (2003). Cardiac autonomic reactivity and salivary cortisol in men and women exposed to social stressors: Relationship with individual ethological profile. Neuroscience \& Biobehavioral Reviews, 27(1-2), 179-188. https://doi.org/10.1016/S0149-7634(03)00019-8

Soroka, S., Fournier, P., \& Nir, L. (2019). Cross-national evidence of a negativity bias in psychophysiological reactions to news. Proceedings of the National Academy of Sciences, 116 (38), 18888-18892. https://doi.org/10.1073/pnas.1908369116

Soroka, S., Fournier, P., Nir, L. \& Hibbing, J. (2019).

Psychophysiology in the study of political communication: An expository study of individual-level variation in negativity biases. Political Communication, 26(2): 288-302. https://doi.org/10.1080/10584609.2018.1493008
Soroka, S., \& McAdams, S. (2015). News, politics and negativity. Political Communication, 32(1), 1-22.

Taber, C. S., \& Lodge, M. (2006). Motivated skepticism in the evaluation of political beliefs. American Journal of Political Science, 50(3), 755-769. https://doi.org/10.1111/j.15405907.2006.00214.x

Task Force of the European Society of Cardiology and the North American Society for Pacing and Electrophysiology. (1996). Heart rate variability. Annals of Noninvasive Electrocardiology, 1(2), 151-181. https://doi.org/10.1111/ j.1542-474X.1996.tb00275.x

Thayer, J. F., Friedman, B. H., \& Borkovec, T. D. (1996). Autonomic characteristics of generalized anxiety disorder and worry. Biological Psychiatry, 39(4), 255-266. https://doi.org/ 10.1016/0006-3223(95)00136-0

Thayer, J. F., \& Lane, R. D. (2000). A model of neurovisceral integration in emotion regulation and dysregulation. Journal of Affective Disorders, 61(3), 201-216. https://doi.org/10.1016/ S0165-0327(00)00338-4

Vraga, E. K. (2015). How party affiliation conditions the experience of dissonance and explains polarization and selective exposure. Social Science Quarterly, 96(2), 487-502. https://doi.org/10.1111/ssqu.12138

Westen, D., Blagov, P. S., Harenski, K., Kilts, C., \& Hamann, S. (2006). Neural bases of motivated reasoning: An fMRI study of emotional constraints on partisan political judgment in the 2004 U.S. presidential election. Journal of Cognitive Neuroscience, 18(11), 1947-1958. https://doi.org/10.1162/ jocn.2006.18.11.1947

Zanna, M. P., \& Cooper, J. (1974). Dissonance and the pill: An attribution approach to studying the arousal properties of dissonance. Journal of Personality and Social Psychology, 29(5), 703-709. https://doi.org/10.1037/ h0036651 